\title{
Expresiones faciales de la emoción
}

\section{Paul Ekman \\ Harrieh Oster}

FunNte: Annual Review of Psycbology, 30, 527-554, 1979.

\section{Indice}

Introducción

Los estudios transculturales y el problema de la universalidad

- Datos observados

- Cuestiones sin formular, o $\sin$ resolver

Estudios evolutivos

- Datos observados

- Cuestiones sin formular, o sin resolver

Medición facial

- Medición del tono muscular

- Medición de la acción visible

- Selección con base teórica

- Selección con base inductiva

- Selección con base anatómica

- Otras medidas faciales

Exactitud

- Datos observados

- Cuestiones sin formular, o sin resolver

Retroalimentación facial

Control neural y correlatos autónomos de la expresión facial

- Correlatos psicofisiológicos

- La cara y el cerebro

Direcciones futuras 


\section{INTRODUCCION}

La investigación sobre la expresión facial de la emoción ha sido episódica. El tema floreció entre 1920-1940, atrayendo la atención de renombrados psicólogos: por ejemplo, Allport, Boring, Goodenough, Guilford, Hunt, Klineberg, Landis, Munn, Titchener, Woodworth. Sin embargo, los resultados obtenidos no fueron definitivos. En opinión de los autores que han revisado el tema $(15,76,127)$, no hubo respuestas consistentes a las cuestiones fundamentales planteadas sobre la exactitud de la información proporcionada por la expresión facial, su universalidad y posible innatismo, etc. Durante los veinte años siguientes, el tema fue poco estudiado, exceptuando los hallazgos de Schlosberg de que los juicios de la emoción en categorías pueden ordenarse según dimensiones básicas. Algunos estudios recientes han contribuido a reavivar el interés por la expresión facial.

Tomkins $(128,129)$ propuso una teoría racional para el estudio de la cara como medio para conocer la personalidad y la emoción. También mostró (130) que los observadores podían alcanzar un alto grado de acuerdo al juzgar emociones si las expresiones faciales se seleccionaban cuidadosamente para exhibir lo que él creía que son afectos faciales innatos. Tomkins influyó notablemente en Ekman e Izard, ayudándoles a proyectar sus primeros estudios transculturales sobre la expresión facial. La evidencia de la universalidad de la expresión facial volvió a despertar el interés del tema en la Psicología y Antropología.

La certeza de la existencia de universales en la expresión facial no sólo está de acuerdo con la teoría de Tomkins, sino también con el interés surgido recientemente en la aplicación de los conceptos y métodos etológicos al estudio de la conducta humana. La etología humana, interesada en las bases biológicas de la conducta, recibió con agrado la evidencia de constantes en la conducta social en diferentes culturas. Los etólogos humanos proporcionaron los primeros «catálogos» detallados que describen la conducta facial en situaciones naturales. Actualmente los psicólogos evolutivos que investigan la vinculación, la interacción madre-hijo y el desarrollo de las emociones han empezado a estudiar la expresión facial.

El interés por la expresión facial refleja también la popularidad que en estos momentos tiene la comunicación no verbal. Aunque la mayoría de las investigaciones realizadas en este campo se han centrado en el movimiento de manos y cuerpo, dirección de la mirada o postura, varios estudios han incluido algunas medidas faciales o han utilizado un enfoque basado en juicios para evaluar la cara.

Algunos trabajos recientes han revisado la bibliografía sobre expresión facial hasta 1970. Ekman, Friesen y Ellsworth (52) volvieron a analizar muchos de los experimentos realizados entre 1914 y 1970. Encontraron -contrariamente a la afirmación de Bruner y Tagiuri (15) - que los datos proporcionaban respuestas consistentes y positivas a las principales cuestiones planteadas sobre la terminología utilizada para la descripción de la expresión facial, la influencia del contexto en los juicios sobre la expresión facial, la precisión de los juicios y las semejanzas transculturales. Para 


\section{8}

otras revisiones sobre expresión facial, véase: (30) sobre niños de distintas edades; $(31,104)$ sobre primates no humanos; (44) sobre diferentes culturas; (77) sobre teorías de la emoción.

Nos centraremos principalmente en los estudios realizados con posterioridad a estas revisiones. Discutiremos cuatro aspectos que consideramos de la mayor importancia, ya sea porque su significación teórica sigue vigente (estudios transculturales, evolutivos y de grado de acuerdo) o por los recientes avances metodológicos (medición facial).

También consideraremos, brevemente, la investigación sobre la influencia de la retroalimentación y de los correlatos neurológicos de la expresión facial. En vez de proporcionar un estudio exhaustivo de cada una de las áreas, resumiremos los hallazgos importantes, señalaremos las deficiencias en el conocimiento empírico y plantearemos cuestiones para futuros estudios.

\section{ESTUDIOS TRANSCULTURALES; EL PROBLEMA DE LA UNIVERSALIDAD}

\section{Datos observados}

1. Observadores de distintas culturas denominan de la misma forma ciertas expresiones faciales. Algunos estudios (revisados en 44) intentaron mostrar diferencias transculturales en el juicio de los observadores de expresiones faciales aisladas. De hecho, los resultados o bien fueron ambiguos o demostraron la existencia de semejanzas transculturales. Las pruebas más consistentes las obtuvieron los investigadores que utilizaron criterios descriptivos explicitos (basados en teorías o resultados empíricos) para seleccionar fotografías de expresiones representativas de cada emoción. Estas fotografías se enseñaron a observadores que tenían que elegir de una lista de términos relacionados con la emoción aquel que mejor describiera cada expresión. La mayoría de los observadores de cada cultura interpretaron las expresiones faciales como portadoras de las mismas emociones [ 5 culturas literatas $(43,55) ; 9$ culturas literatas (77)]. Experimentos similares han proporcionado resultados comparables en Malasia (11) y en dos estados de la Unión Soviética (informe no publicado de T. Niit y J. Valsiner).

Dos estudios investigaron los juicios sobre la intensidad de la expresión emocional. En ambos se dio un alto grado de acuerdo entre miembros de culturas literatas $(44,108)$.

A pesar de esta evidencia, podría argumentarse que las expresiones faciales de la emoción son señales sociales variables culturalmente y que la coincidencia en los juicios se puede atribuir únicamente a una experiencia común de aprendizaje. Según esta interpretación, la exposición a las mismas representaciones de la emoción a través de los medios de comunicación enseñaría a la gente de cada cultura cómo denominar las expresiones faciales. Esta explicación fue refutada por estudios realizados en culturas aisladas, preliteratas y no expuestas a los medios de comunicación: la Fore del Sur en Papua/Nueva Guinea y la Dani, en el oeste del Irán [Heider y 
Heider, referencia en (44)]. Estas culturas escogían, para una emoción determinada, la misma expresión facial que miembros de culturas literatas.

Una limitación de estos estudios transculturales es que las expresiones faciales mostradas no eran genuinas, sino que eran poses de sujetos especialmente instruidos para exhibir una emoción determinada o para mover unos músculos concretos. Un intérprete de estos estudios (94) sugirió que la universalidad en los juicios sobre la expresión facial podría limitarse únicamente a estas expresiones estereotipadas, preparadas. Dos experimentos disienten de esta interpretación. Winkelmayer, et al. (138) eligieron muestras de películas que recogían entrevistas con sujetos normales y esquizofrénicos con la intención de ver si miembros de distintas culturas diferían en sus juicios sobre la emoción cuando se les presentaban expresiones espontáneas en vez de poses. No hubo diferencias globales entre observadores americanos, ingleses y mexicanos. Sin embargo, estos últimos eran menos exactos que los demás al juzgar la expresión facial de sujetos normales, aunque no ocurría lo mismo cuando juzgaban expresiones faciales de esquizofrénicos. Esta diferencia, no prevista, puede deberse al idioma y/o la cultura, y no ha sido replicada. Resultados más claros se obtuvieron en un estudio de Ekman (43) en el que observadores americanos y japoneses tenían que juzgar si la observación de una película que producía estrés o una película neutra se reflejaba en la expresión facial de los sujetos americanos y japoneses que la veían. Los observadores de las dos culturas estuvieron igualmente de acuerdo aunque juzgaran a miembros de diferentes culturas. Además, las personas que fueron juzgadas correctamente por observadores americanos, lo fueron también por observadores japoneses (correlación superior a .75). Este experimento se replicó con sujetos y observadores diferentes.

2. Miembros de diferentes culturas muestran las mismas expresiones faciales cuando experimentan la misma emoción a no ser que interfieran normas expresivas específicas de cada cultura. Aunque muchos estudios se han preocupado de comparar los juicios de observadores de diferentes culturas sobre la expresión facial, muy pocos han comparado las expresiones faciales exhibidas por miembros de culturas distintas en situaciones semejantes. Sin estudios sobre mediciones de la actividad facial no es posible determinar qué aspectos específicos de las expresiones faciales son universales, en qué contexto social aparecen, ni cómo intervienen las normas culturales en la manifestación de la expresión emocional. Estas cuestiones se refieren tanto a las expresiones faciales preparadas (poses) como a las espontáneas. Sólo ha habido un estudio sobre ambas.

Ekman y Friesen (47) encontraron que miembros de un grupo preliterato de Nueva Guinea mostraban los mismos movimientos faciales que miembros de culturas literatas cuando posaban con una emoción concréta. Ekman (43) y Friesen (61) comprobaron que los sujetos japoneses y americanos mostraban las mismas acciones faciales cuando veían solos una película que producía estrés o una película neutra. Sin embargo, tal como el conocimiento de las normas expresivas (display rules) de las dos culturas permitía predecir, 
los sujetos japoneses sonreían más y mostraban un mayor control de la expresión facial que los americanos si estaba presente una persona de más autoridad.

\section{Cuestiones sin formular, o sin resolver}

1. ¿Cuántas emociones tienen una expresión facial universal? Investigaciones realizadas en culturas literatas encontraron expresiones faciales características para la ira, el desagrado, la alegría, la tristeza (o malestar), el miedo y la sorpresa $(11,43,44,55,77$, 108). Izard (77) añadió a las anteriores el interés y la vergüenza, pero el examen de las fotografías sugirió que era la posición de la cabeza, y no la expresión facial, la que proporcionaba los indicios para el reconocimiento de estas emociones. No ha habido otros estudios transculturales sobre el interés y la vergüenza. En las culturas preliteratas estudiadas, el miedo y la sorpresa se diferenciaban de la ira, la tristeza, la felicidad o el desagrado, pero se confundían entre sí tanto en la denominación como en la pose (44). En resumen, únicamente hay una evidencia clara de universalidad en las expresiones de alegría, ira, desagrado, tristeza y la mezcla de miedo/ sorpresa. Quizás investigaciones posteriores revelen la existencia de expresiones faciales universales para otras emociones.

2. ¿Cuántas expresiontes universales pueden distinguirse para cualquier emoción? Tomkins $(128,129)$ formuló la hipótesis de que cada emoción tendría a la vez expresiones universales y específicas de cada cultura, pero no describió con detalle la apariencia de estas últimas. Los estudios transculturales sólo utilizaron algunos ejemplos de cada expresión emocional y no analizaron los juicios de los observadores para ver.si las distintas versiones de cada expresión se juzgaban diferentemente.

3.' ¿Hay grandes diferencias culturales en la expresión facial? La mayoría de los informes que existen sobre una variabilidad cultural extrema en las expresiones de la emoción proceden de observadores aislados que no controlaron los sesgos debidos al observador ni al muestreo, ni tuvieron en cuenta las normas expresivas [Birdwhistell, LaBarre, Leach, Mead y Montague, revisados en $(44,45)]$. Un estudio cuantitativo de las diferencias culturales es el de Ekman y Friesen $(43,61)$, citado anteriormente, en el que encontraron que las expresiones faciales de sujetos japoneses y americanos diferían en una situación social, pero no cuando los mismos sujetos estaban solos. Estos resultados confirmaron la hipótesis de los autores de que una de las principales fuentes de variación cultural en la expresión facial son las normas expresivas que la controlan en diferentes contextos y que se aprenden socialmente. En otro estudio sobre normas expresivas, Heider (73) confirmó su predicción de que en una cultura del oeste del Irán, y no en otras, se manifestarían expresiones de desagrado en vez de ira cuando se pedía que se realizaran poses de temas relativos a la ira. No ha habido nuevos estudios transculturales de normas expresivas. El estudio de un anuario fotográfico y algunas conversaciones (116) proporcionaron pruebas de la existencia de un «dialecto» en la expresión facial de 
pautas de sonrisa entre los estadounidenses del sureste. El origen y la interpretación de este dialecto no están claros.

Ekman 43) postuló que los estímulos evocadores aprendidos para cada emoción eran otra fuente de variación cultural, pero planteó la posibilidad de que éstos tuvieran algunas características subyacentes comunes. Boucher y Cunningham (informe no publicado) hallaron pruebas de semejanzas -aunque no encontraron las diferencias pensadas - en los estimulos inductores específicos de algunas emociones en culturas completamente distintas. En resumen, probablemente haya importantes diferencias culturales en la expresión facial, diferencias que pueden atribuirse al aprendizaje, pero no se sabe cuáles son ni cómo se originan.

4. ¿Con qué frecuencia la gente -en situaciones naturalesmuestra realmente pautas universales características de la expresión facial? ¿Estas expresiones son frecuentes o poco comunes? ¿Varía su aparición en función de la cultura, el sexo, la edad o contextos sociales determinados? Todas estas cuestiones exigen una medición detallada de las expresiones faciales que aparecen en circunstancias específicas en las diferentes culturas y el conocimiento de las normas expresivas propias de cada una de ellas. Estos datos, sin embargo, no se conocen ni siquiera en una sola cultura.

5. ¿Cuáles son los orígenes filogenéticos $y / u$ ontogenéticos de la expresión facial? ¿Por qué se activan determinados músculos faciales en expresiones emocionales concretas? Por ejemplo, ¿por qué se elevan las comisuras de los labios en estados de felicidad y descienden en la tristeza y no al revés? El hallazgo de la existencia de expresiones faciales universales se ha interpretado como prueba de que estas expresiones son señales especializadas innatas, programadas $(37,42,104,128)$. Otros autores $(2,103)$, por el contrario, han pensado que las expresiones faciales de los adultos derivan ontogenéticamente del aprendizaje constante de la especie y de las respuestas biológicamente adaptativas del recién nacido: movimientos relacionados con reacciones sensoriales, respuestas de defensa y orientación, llanto, succión, etc.

Los datos decisivos para la comprensión del origen de las expresiones faciales de la emoción - el estudio longitudinal con mediciones detalladas de los movimientos faciales de niños en situaciones diferentes y culturas no relacionadas - sólo existen parcialmente. La comparación minuciosa de niños ciegos y videntes revelaría la importancia de la imitación visual y la utilidad adaptativa de los movimientos faciales implicados en la visión para el desarrollo de la expresión facial. Los estudios con niños ciegos de nacimiento (revisados en 30) han proporcionado la mejor prueba de que la imitación directa no es necesaria para el desarrollo de la sonrisa y el llanto. Sin embargo, las descripciones de los movimientos faciales reales que corresponden a estas y otras emociones (por ejemplo, la sorpresa, la ira) en niños ciegos han sido vagas e imprecisas. Los informes de que los niños ciegos muestran una expresividad facial menor que los videntes $(30,59)$ tạmbién necesitan una descripción detallada. 


\section{2}

\section{ESTUDIOS EVOLUTIVOS}

La mayor parte de las investigaciones sobre la expresión facial en niños se han preocupado del curso del desarrollo emocional. ¿A qué edad y en qué orden aparecen determinadas emociones? Por desgracia, los criterios conductuales con que se han «reconocido» y etiquetado algunas respuestas emocionales son con frecuencia subjetivos e imprecisos, prestando muy poca atención a la descripción detallada de los movimientos faciales en sí mismos. La mayoría de los primeros estudios carecían también de medidas independientes y convergentes para evaluar el supuesto estado emocional del niño. Algunos estudios recientes han intentado subsanar estos problemas metodológicos $(26,74,91,136,142)$. A pesar de todo, todavía no se sabe cuándo aparecen por primera vez las expresiones faciales universales y características de algunas emociones, ni cómo se desarrollan. Parte del problema estriba en que las cuestiones que las investigaciones con lactantes han dejado sin respuesta no se han seguido planteando con niños de otras edades.

\section{Datos observados}

1. La musculatura facial es furcional y está completamente formada en el momento de nacer. Muchos observadores se han sorprendido de la considerable movilidad facial de los recién nacidos $(63,72)$. Utilizando un refinado sistema de medida (descrito debajo), Oster y Ekman (100) confirmaron que casi todas las acciones de determinados músculos en adultos podían identificarse y discriminarse con exactitud en recién nacidos, aun en el caso de que éstos fueran prematuros. Se han encontrado pruebas de la existencia de patrones organizadores y temporales en movimientos expresivos tales como la sonrisa, fruncimiento de cejas y pucheros $(81,99,100)$.

2. En la primera infancia ya bay expresiones faciales distintivas semejantes a ciertas expresiones adultas. El llanto, expresión universal del malestar, está presente en el nacimiento, pero las señales faciales de malestar se han descrito con muy poco cuidado después de Darwin y ni siquiera se han estudiado los cambios desarrollados en las caras de llanto. No se sabe si los diferentes movimientos faciales corresponden a clases de llanto distintas acústicamente o a diferentes orígenes del malestar. Los niños recién nacidos muestran expresiones semejantes al desagrado de los adultos como respuesta a los sabores displacenteros $(103,124)$. Estas respuestas faciales se han encontrado también en niños anencefálicos e hidrocefálicos, lo que hace pensar que se originan en el tronco cerebral (124). No se conocen los procesos por los que estas reacciones faciales llegan a asociarse con una amplia gama de evocadores psicológicos. La reacción de sobresalto se puede provocar en el recién nacido mediante una estimulación repentina e intensa y a menudo ocurre como una descarga espontánea durante el sueño no-REM. No hay acuerdo sobre si el sobresalto sería una respuesta emocional relacionada con la sorpresa o un reflejo fisiológico $(128,135,140)$. La respuesta 
facial es totalmente distinta a la sorpresa y se dice que no cambia en toda la vida.

Contrariamente a lo que antes se creía, las sonrisas del recién nacido no se producen ni por azar ni por burbujas de gases. Se dan durante el sueño REM y parecen reflejar fluctuaciones periódicas y endógenas de la actividad del SNC $(56,122,139)$. La sonrisa social, por ejemplo, la sonrisa de un niño atento y con los ojos fijos en la persona encargada de su cuidado, aparece por primera vez a las 3 ó 4 semanas (139). La sonrisa social abierta y clara surge durante el tercer mes $(56,139)$. Se ha observado la sonrisa del segundo al tercer mes en diferentes situaciones experimentales, sugiriéndose que refleja un proceso cognitivo activo, «maestría» y eficacia $(102,118,121,122,137)$. Alrededor del inicio del cuarto mes la sonrisa se empieza a reservar para las personas más directamente implicadas en el cuidado del niño $(1,12)$. Con excèpción del estudio de Wolff, ya clásico, se sabe muy poco de los cambios desarrollados en la morfología de la sonrisa o de las diferencias - si es que las hay- en la aparición de la sonrisa «social», la sonrisa «juguetona» y la sonrisa de «dominio cognitivo» $(10,133)$. La risa aparece por primera vez hacia los cuatro meses. La mayoría de los estudios realizados se han centrado en los cambios y en los determinantes de la risa $(121,122)$. El estudio de niños afectados por el síndrome de Dow ha contribuido a la comprensión de los mecanismos que subyacen a la sonrisa y la risa (32).

3. Los niños de 364 meses muestran respuestas diferenciadas a las expresiones faciales. Los primeros estudios (30) indicaban que los niños no empiezan a discriminar expresiones faciales diferentes hasta los 5 ó 6 meses. Algunos estudios recientes han encontrado diferencias en la fijación visual ante diapositivas que presentaban caras alegres, neutras o enfadadas (84), y caras de sorpresa frente a caras alegres (143) a los 3 ó 4 meses. No se sabe realmente a qué aspectos de la cara responden los niños, ni siquiera si perciben los estímulos (salvo quizás la sonrisa) como expresiones emocionales significativas. La medición de las respuestas emocionales de los niños y las pautas de escudriñamiento de diferentes expresiones faciales pueden ayudar a resolver esta cuestión. A los tres meses los niños llegan a ponerse «serios» o disgustados si la persona que está con ellos presenta una cara impasible, lo que sugiere una sensibilidad hacia la vivacidad y una responsividad a la conducta facial en una situación natural $(14,123,131)$. Un estudio detallado de las respuestas del niño a las expresiones faciales dinámicas, en pautas temporales, y a menudo exageradas de los adultos que le cuidan (cf. 125) podría revelar una gran sensibilidad a las diferencias de los movimientos expresivos.

4. La imitacion de algunos movimientos faciales es posible a edad muy temprana. Estudios recientes sugieren que los niños de 263 semanas pueden imitar diferencialmente acciones como abrir la boca y sacar la lengua o adelantar los labios (97) pero no hay acuerdo sobre el posible mecanismo que subyace a esta acción $(80,97)$. No se sabe si los niños recién nacidos pueden imitar las principales acciones utilizadas en la expresión de las emociones ni qué papel desempeña la imitación en el desarrollo normal o en la 


\section{4}

«sincronización fina» de la expresión facial. Este papel es sugerido por los recientes hallazgos de Kaye y Marcus (82) que demuestran que los niños de 6 meses acomodan gradualmente su actuación en una serie de ensayos para ajustarse a los movimientos que se les presentan como modelo (salvas de abrir y cerrar la boca). La mayoría de las acciones faciales específicas encontradas en la expresión emocional pueden imitarse hacia los 5 años (105).

5. Los niños de preescolar saben cómo son la mayoría de las expresiones faciales frecuentes, la que significan y qué situaciones suelen desencadenarlas. Los hallazgos generales sobre reconocimiento, discriminación, representación de papeles afectivos y estudios empáticos ponen de manifiesto que la ejecución mejora entre los 3 y los 10 años $(30,67,75)$. Las habilidades para imitar y reproducir voluntariamente expresiones faciales para satisfacer a los jueces adultos también se incrementan con la edad $(30,70)$. La expresión de alegría es una de las más fáciles de reconocer y reproducir, mientras que la de miedo es de las más difíciles. En la mayor parte de los estudios con niños se han utilizado tareas de tipo cognitivo, centrándose más en el conocimiento de las expresiones emocionales que en la medición de expresiones emocionales espontáneas. Sin embargo, algunos estudios sobre la empatía han comprobado que las expresiones faciales espontáneas de niños en edad preescolar reflejan las emociones mostradas por otros [(70), revisado en (75)]. Las expresiones no verbales espontáneas de estos niños mientras observan diapositivas que provocan emociones pueden ser «descodificadas» por otros niños de preescolar, por lo menos en términos de lo placentero o displacentero de la reacción del «emisor» (16). Pero no se han realizado mediciones directas de la expresión facial en los estudios de codificación/descodificación. Los únicos estudios directos del comportamiento facial en niños provienen de una perspectiva etológica, como se verá más adelante.

6. La expresión facial puede desempeñar un papel importante en el desarrollo de la comunicación social. Cada vez se tiende más a considerar al niño como un ser activo, equipado con una capacidad señalizadora básica y útil para asegurar ciertas clases de intercambios promovedores del apego entre él y sus cuidadores $(1,12$, $14,92,131)$. Se considera a la expresión facial como el elemento esencial de este sistema señalizador.

Los estudios etológicos de la interacción social en el cuidado diario o en la guardería se han centrado generalmente en el repertorio facial o corporal de acciones asociadas con situaciones agonísticas, juegos turbulentos y en la interacción social con adultos y compañeros (10). Los etólogos discuten estos actos desde el punto de vista de su presunta motivación y función señalizadora. Sin embargo, hay muy pocos datos cuantitativos sobre qué movimientos expresivos determinados desempeñan realmente una función señalizadora. Además, los etólogos tampoco han relacionado sistemáticamente los movimientos faciales mostrados en estas acciones con las expresiones emocionales. Una excepción a todo esto es un estudio experimental reciente, enfocado etológicamente (28), que muestra que algunas configuraciones faciales «agresivas» utilizadas por los niños para defender un objeto deseado, predicen tanto su propia 
conducta como el comportamiento posterior de su compañero. Las observaciones de que la presencia de otros puede tener un efecto facilitador en expresiones emocionales como el llanto (10) y el humor (29) sugieren un control social cada vez mayor sobre la expresión emocional.

\section{Cuestiones sin formular, o sin resolver}

1. ¿A qué edad se puede inferir una emoción de la expresión facial en la primera infancia? La mayor parte de los psicólogos han creído que los niños pequeños carecen de prerrequisitos cognitivos para la expresión de la emoción. Esta creencia divide el espectro nativista/empirista (e.g., 2, 63, 103), aunque ha habido una gran variedad de opiniones sobre los prerrequisitos cognitivos supuestamente necesarios para la experiencia de «emociones verdaderas», sobre la edad en que se alcanzan y sobre los mecanismos ontogenéticos posiblemente implicados. Ciertos trabajos recientes $(56,90$, $107,121)$ han interpretado algunos movimientos expresivos que se producen en la primera infancia, por ejemplo, llorar y sonreír, como precursores reflejos, puramente pasivos, de las expresiones emocionales posteriores. Se dice que no hay emociones «genuinas» hasta la aparición de los primeros signos de procesamiento cognitivo activo o «conciencia», alrededor del tercer mes $(56,121)$, o hasta la aparición de la "conciencia de sí mismo», alrededor de los dieciocho meses (20). Diversos investigadores, aunque no niegan la importancia de estas adquisiciones cognitivas, mantienen que la emoción ya está presente en el momento de nacer $(79,128,129)$, - sugieren una transición más gradual de la causalidad fisiológica a la psicológica en la expresión emocional $(99,123,140)$. Esta cuestión no puede contestarse con los datos empíricos de que se dispone en la actualidad.

2.' ¿Cuándo aparecen por primera vez expresiones faciales diferenciadas, semejantes a las adultas, para las emociones de interés, sorpresa, tristeza, miedo $e$ ira? Se ha observado un «brillo» en los ojos y la cara de niños recién nacidos atentos a estímulos auditivos y visuales. No obstante, se necesitan estudios más detallados para poder afirmar que la expresión de interés, distinta de las respuestas de orientación y atención, está presente en la primera infancia. La cara típica de sorpresa en adultos se observa raramente en niños menores de un año $(30,135)$, aunque a partir del año y medio los niños pueden responder a situaciones experimentales supuestamente sorpresivas de forma que parecen realmente sorprendidos $(38,74,135)$.

Todavía no podemos especificar cuándo empiezan a aparecer de manera regular las expresiones de emociones negativas determinadas (que no sean el llanto), ni en qué circunstancias naturales suelen ocurrir. Las caras de tristeza y displacer se diferencian en los adultos, pero esta distinción no se ha observado en estudios con lactantes y niños. El «recelo» y el miedo surgen en la segunda mitad del primer año, como se deduce de la aparición de reacciones de duda, evitación o abiertamente negativas en situaciones que anteriormente no inquietaban, como las alturas o la aproximación de un extraño 


\section{6}

$(27,38,56,120,121)$. La ira se infiere a partir de las «rabietas» y actos instrumentales como golpear, tirar y morder $(30,121)$. Pero las expresiones faciales que acompañan a estas respuestas emocionales no se han descrito con detalle. Los investigadores que codifican, según acciones faciales específicas, las respuestas del niño a situaciones provocadoras de emociones $(26,74,91,136,142)$ no han encontrado expresiones diferenciadas de miedo, tristeza o ira, sino caras de atención emocionalmente neutras y caras con elementos de displacer o previas al llanto. En uno de los pocos estudios en que se intentó provocar varias emociones negativas determinadas (142), las reacciones de los lactantes no se pudieron distinguir basándose únicamente en la expresión facial. Un sistema de codificación más detallado podría revelar precursores de las expresiones adultas de ira, tristeza o miedo en las caras de llanto o previas al llanto provocadas por diferentes hechos o asociadas con otras conductas indicativas de estas emociones.

Como se indicó anteriormente, los niños de cinco años pueden simular satisfactoriamente expresiones de ira, miedo y tristeza. Pero no ha habido ningún estudio sistemático de la aparición real de expresiones de emociones negativas concretas en situaciones naturales o en el laboratorio. Aparentemente, el llanto permanece como expresión predominante de sentimientos negativos intensos durante toda la primera infancia. Sin embargo, ningún estudio ha investigado la hipótesis de Tomkins (129) de que las distintas emociones negativas van acompañadas de vocalizaciones y caras de llanto diferentes. No está claro si los niños lloran porque todavía no «utilizan» expresiones faciales más concretas (que, sin embargo, pueden producir voluntariamente), o porque a esta edad todos los efectos negativos producen displacer o se combinan con él.

3. ¿Cuándo -y cómo- se adquiere el control voluntario de la expresión facial de la emoción? El desarrollo del control voluntario y de las «normas expresivas», definidas culturalmente, que regulan la manifestación de las emociones sigue siendo una terra incognita, con algunas observaciones impresionistas que sugieren una transición gradual de la expresión automática, sin control, de la primera infancia a la más modulada, sutil y voluntaria de niños mayores y adultos. El primer paso probablemente sea la utilización instrumental (no completamente consciente) del llanto y la sonrisa, algunas veces a los dos o tres meses, como sugieren las impresiones subjetivas del llanto «fingido» (141), la evidencia de que tanto el llanto como la sonrisa pueden controlarse mediante refuerzo social (64), y los informes que apuntan que los niños empiezan a darse cuenta de la eficacia de su propia conducta señalizadora (6) en los seis primeros meses de vida. Hacia el final del primer año se observa lo que parecen ser sonrisas utilizadas como saludos sociales, «rabietas» deliberadas $y$ esfuerzos visibles por contener o reprimir las lágrimas. Sin embargo, no se han examinado a fondo las acciones faciales específicas realizadas en estas conductas.

Como se ha indicado, en niños de preescolar ya existe, de alguna manera, una forma de control voluntario: la imitación deliberada o la exhibición de expresiones faciales cuando la emoción correspondiente está (presumiblemente) ausente. Un estudio reciente del 
conocimiento de las normas expresivas sociales (106) encontró que éste aumentaba entre los seis y los diez años. No conocemos ningún estudio que haya investigado directamente los esfuerzos del niño para controlar la expresión emocional o su utilización de normas expresivas. A pesar de la afirmación general de que la retroalimentación social (por ejemplo, «los niños mayores no lloran») juega un papel decisivo en el moldeamiento de las tendencias del niño a regular la expresión emocional, no tenemos datos objetivos sobre la cantidad y clase de la retroalimentación social que realmente reciben los niños en respuesta a sus expresiones faciales, ni de hasta qué punto los padres, otros adultos y los mismos compañeros sirven como modelos directos.

\section{MEDICION FACIAL}

Como ya se ha indicado repetidamente, muchas de las cuestiones centrales en la investigación transcultural y evolutiva requieren la medición de la actividad facial en sí misma y no pueden contestarse confiando únicamente en el acuerdo de los juicios de los observadores de la emoción. Recientemente se han desarrollado métodos que permiten medir dos aspectos - diferentes aunque relacionados - de la actividad facial: los cambios en el tono muscular y las acciones visibles.

\section{Medición del tono muscular}

Schwartz y sus colaboradores (115) han demostrado que la electromiografía superficial (EMG) es sensible a las diferencias entre emociones evocadas y estados emocionales y puede distinguir a los depresivos de los sujetos normales. Los electrodos para la EMG se colocaron en las áreas faciales en que, de acuerdo con las teorías $(49,128,129)$, se esperaba una actividad diferente para las emociones en estudio. Aunque una posición determinada de los electrodos puede, aparentemente, discriminar entre 2 ó 3 emociones, no es seguro que la EMG pueda distinguir 5 ó 6 emociones. Un trabajo en realización de Ekman, Schwartz y Friesen sobre la relación entre la EMG y la actividad facial visible sugiere que la EMG permite registrar cambios en el tono muscular que apenas son visibles 0 , incluso, totalmente invisibles.

La medición electromiográfica de la actividad facial puede ser útil cuando el investigador sea capaz de especificar por adelantado las emociones que le interesan, cuando la interferencia del experimentador sobre el sujeto no tenga importancia y cuando no sea probable que el sujeto mueva la cara (los electrodos, pasta y cinta, inhiben los movimientos y pueden romperse si hay movimientos musculares violentos). La EMG puede utilizarse cuando se activa la emoción por la imaginación, el recuerdo, la audición, la visión de una película, etc. Además, es el único método capaz de probar la afirmación de Birdwhistell (8) de que hay diferencias individuales 
estables en las pautas de tensión muscular sostenida cuando la cara está en reposo.

\section{Medición de la acción visible}

Los primeros intentos de medir los cambios faciales visibles (revisados en 52, cap. 16) fueron ignorados por los autores posteriores. Estos primeros intentos de medir la actividad facial no justificaban la elección de unidades de medida. Sin embargo, como Altmann hace notar «... qué paso de nuestra investigación puede ser más decisivo que la elección de unidades de comportamiento. En ella descansan todos los registros posteriores de las interacciones comunicativas y cualquier conclusión que pueda extraerse de éstos...» (3, p. 501). La selección de unidades conductuales se ha basado en teorías, observaciones inductivas o en la anatomía facial.

- Selección basada en teorias. Ekman, Friesen y Tomkins (53), en su Técnica de Valoración de la Afectación Facial [Facial Affect Ssoring Technique (FAST)], especificaban los componentes que diferenciaban seis expresiones emocionales universales. La utilidad del FAST se demostró en estudios que relacionaban expresiones faciales de los sujetos y respuestas del SNA, condiciones experimentales y juicios de los observadores. El FAST no es, sin embargo, una herramienta de uso general. No puede utilizarse para determinar si acciones diferentes de las descritas son relevantes para una emoción determinada, ni para estudiar los cambios en el desarrollo, ni las diferencias individuales en la expresión emocional. También pueden aplicarse al FAST las dos primeras críticas, especificadas más abajo, a los sistemas basados en la inducción. El Manual de Valoración de la Expresión Facial [Facial Expression Scoring Manual, (FESM)] de Izard (comunicación personal), que sigue el mismo enfoque general que el FAST, probablemente tenga las mismas limitaciones. Algunos investigadores (por ejemplo 74; Izard, comunicación personal) han utilizado sistemas basados en teorías [por ejemplo, los materiales desarrollados por Ekman y Friesen (49) para el entrenamiento clinico, o el FESM de Izard] para medir las expresiones emocionales o sus componentes en niños de diferentes edades. Este enfoque tiene los mismos inconvenientes expresados anteriormente para el FAST. Además, el hecho de utilizar en la investigación infantil un sistema de medición facial con base teórica y derivado de datos obtenidos en adultos plantea problemas metodológicos adicionales. Pero lo más grave es que este enfoque no puede revelar cómo se desarrollan las expresiones adultas en toda la cara e ignora los posibles precursores de éstas.

- Selección con base inductiva. A partir de la observación de lactantes $(98,142)$, niños $(9,13,66,93)$, adultos normales y pacientes psiquiátricos (66) se han elaborado listas de acciones faciales, con cierto solapamiento. Estos sistemas se utilizan para construir «etogramas» o catálogos de las conductas sobresalientes en el repertorio comunicativo. El sistema de Blurton-Jones ha sido adoptado, con algunas variaciones, por cierto número de psicólogos evolutivos. 
Sin embargo, todos ellos tienen fallos metodológicos importantes si los consideramos como sistemas de medición de carácter general.

Todos son incompletos y no explican lo que se ha deshechado ni por qué. Todos incluyen - sin mencionarlo- lo mismo acciones musculares sencillas que movimientos complejos que abarcan varias acciones independientes. Algunas veces se ha dado a las unidades conductuales nombres cargados de interpretación (por ejemplo, «ceño de ira»), lo que hace difícil el estudio objetivo del significado de la acción. Muchas unidades están descritas de forma vaga, con lo que otros investigadores no pueden saber si están codificando los mismos movimientos. Las descripciones de algunas acciones son anatómicamente incorrectas. Finalmente, las diferencias fisiognómicas, individuales, raciales o debidas a la edad pueden dificultar la identificación de ciertas acciones descritas en términos de configuraciones estáticas (por ejemplo, «boca alargada»).

- Selección con base anatómica. Puesto que cada movimiento facial es el resultado de acciones musculares, un sistema para la descripción de la expresión facial puede tener mayor alcance si las unidades de medida se basan en el conocimiento anatómico de las acciones musculares que cambian la expresión. Cualquier movimiento facial complejo puede puntuarse analíticamente según las acciones musculares mínimas que, conjuntamente, lo producen. Esta lógica ha sido adoptada por tres investigadores.

Seaford (116) proporcionó una excelente y detallada crítica de los riesgos de los sistemas inductivos o derivados de teorías. Su descripción de la variación regional de la expresión facial demostró la utilidad de la aproximación anatómica. Ermiane y Gregerian (57) han desarrollado un sistema de medición facial de carácter general y base anatómica. Sin embargo, no proporcionan información sobre la fiabilidad ni mencionan si el sistema lo puede aprender un investigador por su cuenta. El Sistema de Codificación de las Acciones Faciales [Facial Action Coding System (FACS)] de Ekman y Friesen $(50,51)$ fue ideado como un sistema de carácter general para medir toda conducta facial visible en cualquier contexto, sin limitarse a las acciones relacionadas con la emoción. La lista de unidades mínimas se solapa considerablemente con la de Ermiane y Gregerian. Sin embargo, el FACS especifica las unidades mínimas no sólo según las posibles acciones anatómicas sino también según los movimientos que pueden distinguirse con facilidad. Las personas que aprenden el sistema sin la enseñanza personal de los autores han alcanzado una fiabilidad elevada.

El FACS es lento de aprender y utilizar, ya que requiere la visión repetida y a cámara lenta de las acciones faciales, no siendo adecuado, por tanto, para un proceso de codificación rápido. Por su naturaleza, el FACS incluye más distinciones de las que puedan necesitarse en un estudio concreto, lo que aumenta el esfuerzo y el tedio de la medición. Sin embargo, al estar definidas empíricamente las unidades significativas de la conducta, es posible en un estudio determinado separar algunas de las unidades elementales de medida a pasar por alto distinciones sutiles. Todavía no hay datos empíricos para sostener qué acciones y combinaciones faciales, puntuadas según el FACS, corresponden a emociones determinadas. 


\section{Otras medidas faciales}

Quizás la medida de la actividad facial más popular haya sido la dirección de la mirada, aunque sorprendentemente sólo en raras ocasiones se haya relacionado con la emoción o la expresión facial [excepciones recientes son $(85,86,123,125,136)]$. Aunque se ha estudiado la dilatación pupilar en relación con la emoción, no conocemos ningún estudio de los cambios asociados en la expresión facial. En flujo sanguíneo, la temperatura de la piel y los cambios de coloración en la cara son otras medidas que, hasta ahora, permanecen sin explorar.

\section{EXACTITUD}

¿Cómo podemos determinar si es exacta la información proporcionada por la expresión facial de una persona? Necesitamos algún criterio -que sea independiente de la misma cara - para establecer qué emoción, si es que hay alguna, está ocurriendo en el momento en que se produce la expresión facial. El mayor obstáculo en la investigación de la exactitud ha sido el problema de la validación independiente. Una aproximación corriente ha sido la de preguntar a los sujetos (generalmente de forma retrospectiva) sus estados emocionales y observar si cambia la expresión facial cuando afirman experimentar la emoción A en comparación con la B. Estos autoinformes son propensos al error, ya que los sujetos pueden fracasar al recordar o distinguir las emociones experimentadas -especialmente si transcurren varios minutos antes de hacer el informe. Un sujeto que sienta sucesivamente ira, desagrado y desprecio al contemplar una película podría no -recordar las tres reacciones, su secuencia exacta o el momento de su aparición. Este problema se puede evitar limitando el autoinforme a una distinción más amplia entre emociones placenteras o displacenteras; pero entonces no podemos determinar si las expresiones faciales proporcionan una información precisa sobre una emoción determinada, ya sea placentera o displacentera.

Una segunda aproximación ha sido buscar si las expresiones faciales de los sujetos cambiaban en situaciones diferentes: por ejemplo, películas y diapositivas emocionalmente positivas o negativas, anticipación de una descarga eléctrica o de un ensayo sin descarga, o comentarios amistosos u hostiles hechos por otra persona. Como es improbable que todos los sujetos experimenten la misma emoción ante una situación determinada, lo único que esta aproximación puede demostrar es que posiblemente las expresiones faciales cambien en situaciones placenteras o displacenteras. Para medir la exactitud se ha intentado obtener, previa o posteriormente, otra información sobre el sujeto; pero en este caso puede ser que las expresiones faciales proporcionen información sobre algunos rasgos permanentes además de los estados transitorios. Si determinados cambios en el tono o cualidad de la voz, en los movimientos del cuerpo, o en el lenguaje fueran indicadores infalibles, se podrían utilizar como criterios de la exactitud. Por desgracia, no hay ninguna prueba de 
que estos cambios proporcionen una información más precisa que la obtenida a través de la expresión facial. Similarmente, los cambios en la actividad del SNC o del SNA podrían proporcionar un criterio útil si tuviéramos la evidencia de que distintas pautas de actividad neural acompañan realmente a emociones diferentes. En una sección posterior se revisarán los escasos estudios sobre los correlatos neurales de la expresión facial. Puesto que no hay una forma única e infalible de determinar el «verdadero» estado emocional de un sujeto, es de lamentar que haya habido tan pocos investigadores interesados en realizar mediciones múltiples y convergentes para obtener una información más fiable de la emoción experimentada.

Independientemente del criterio de exactitud utilizado, la información proporcionada por la expresión facial puede estudiarse indirectamente, a través del juicio de observadores (de la emoción experimentada, de las situaciones que la provocan, etc.), o directamente, midiendo la actividad facial (mediante cualquiera de las técnicas descritas en la sección anterior). La medición facial y los juicios de los observadores no proporcionan necesariamente los mismos resultados, aunque se apliquen a las mismas expresiones faciales. La medición directa podría revelar movimientos expresivos que los observadores no serían capaces de captar o interpretar correctamente. Por el contrario, los observadores podrían percibir índices que no estuvieran entre las unidades medidas. Los estudios de juicios de observadores exceden con mucho a los de medición facial, probablemente porque los últimos son más caros y llevan más tiempo que los primeros.

\section{Datos observados}

1. Las expresiones faciales de la emoción pueden proporcionar información exacta sobre la aparición de estados emocionales placenteros a displacenteros. Un nuevo análisis de los estudios hechos entre 1914 y 1970 (52) concluyó que tanto las mediciones faciales como los juicios de los observadores discriminaban con precisión los estados placenteros de los displacenteros. Desde entonces, cierto número de experimentos (citados más abajo) han replicado estos hallazgos, pero no se han ampliado a posibles distinciones entre emociones positivas o negativas determinadas. Hay poca información que haga referencia a los actos faciales específicos que diferencian los estados placenteros de los displacenteros. La mayoría de los investigadores han utilizado los juicios de los observadores sobre la expresión facial sin intentar determinar a qué configuraciones respondian los observadores. Los que midieron directamente la expresión facial no hicieron constar la frecuencia de los actos específicos o de las configuraciones de toda la cara que aparecían en las expresiones que proporcionaban información exacta.

2. Las expresiones faciales se pueden disimular para confundir a un observador sobre las emociones experimentadas. Entre las docenas de experimentos recientes sobre el engaño interpersonal, sólo en $5(48,71,88,95,145)$ se instruyó explícitamente a los sujetos para que ocultaran sus emociones y al mismo tiempo se obtuvieron pruebas, independientes de la cara, de que realmente experimentaban una emoción. Los resultados obtenidos fueron contradictorios, 
debido probablemente a variaciones en la intensidad o en el número de las emociones activadas, la motivación de los sujetos para mentir y la práctica anterior en estos engaños. Sin embargo, los experimentos diferían también en otro sentido: por ejemplo, si los sujetos sabían que estaban siendo registrados en video, si los observadores conocían el posible engaño, si estaban entrenados, o si además de ver las caras escuchaban la voz de los sujetos que mentían. A pesar de la falta de consistencia, ésta parece ser un área importante para futuros estudios.

3. Los individuos difieren en uexpresividad» facial (babilidad de codificación) $y$ en babilidad para juzgar las expresiones faciales (babilidad de descodificación). En estudios de codificación/descodificación se filmó a los codificadores en situaciones emocionales (mientras observaban diapositivas o sufrían descargas eléctricas); los descodificadores (a menudo los mismos sujetos) intentaban inferir después, a partir de cada expresión facial del codificador, la situación que la provocaba (categoría de las diapositivas o intensidad de la descarga), o la calificación de cada codificador de su propia experiencia emocional. Existen acusadas diferencias individuales en el grado de precisión con que se juzgan las expresiones faciales de un sujeto y en el grado de precisión con que un individuo juzga las caras de otros $(17,36,71,89,145)$. Hay una consistencia entre este hallazgo y las observaciones de otros experimentos que no buscaban específicamente las diferencias individuales. Los intentos de estudiar la relación entre las habilidades codificadoras y descodificadoras han proporcionado correlaciones positivas, negativas e insignificantes [véase (62) para una cuidadosa discusión]. Así mismo, se han encontrado resultados inconsistentes en la búsqueda de correlatos de personalidad en las diferencias individuales de las habilidades de codificación y descodificación. La pequeña, pero consistente, superioridad de las mujeres, lo mismo en la codificación que en la descodificación, es una excepción $(68,69)$.

Estos estudios están plagados de problemas metodológicos que pueden explicar algunas inconsistencias en los datos obtenidos. En algunos estudios los sujetos deben juzgar periódicamente su propia experiencia emocional, lo que podría afectar a las expresiones faciales o a la propia experiencia. Otros experimentos no verificaban qué emoción, si es que había alguna, experimentaban los codificadores. Las excepciones son los estudios que obtuvieron calificaciones independientes de las emociones provocadas por los estímulos (36, 71) o que utilizaron medidas psicofisiológicas indicativas de la activación, aunque no de la emoción provocada (88). Con mayor frecuencia, la única medida de la activación emocional es el éxito del observador en inferir el agrado relativo de la condición estimular - la valoración posterior del sujeto de sus propios sentimientos (19, 20, 146). Estos juicios podrían hacerse a partir de índices que no tendrían nada que ver con la expresión facial _por ejemplo, postura, movimientos corporales burdos, o signos faciales de la actividad cognitiva.

Aunque la búsqueda de los correlatos de personalidad de las diferencias individuales en las habilidades de codificación y descodificación implica la estabilidad de estas diferencias, no ha habido nin- 
gún estudio de la fiabilidad test-retest en la habilidad individual de codificación o en las habilidades de codificación y descodificación en los mismos sujetos. Otro problema es que en muchas tareas de descodificación los observadores deben juzgar las expresiones faciales que ocurren durante el lenguaje, omitiendo éste. Sólo los mudos tendrían suficiente experiencia para desarrollar diferencias individuales estables en la descodificación de tales estímulos. Un enfoque bastante diferente aparece en el hallazgo de Schiffenbauer (111) de que el estado emocional del observador influía en la emoción que atribuía a una expresión facial.

\section{Cuestiones sin formular, o sin resolver}

1. ¿Las expresiones faciales pueden proporcionar información precisa de las distinciones entre diversas emociones positivas y negativas? Sólo hay pruebas de que puedan en el caso de las poses faciales.

2. ¿Cuándo podemos esperar que la expresión facial proporcione información precisa sobre la emoción? Los estudios que demuestran que las expresiones faciales de algunas personas son difíciles de juzgar no determinan si la medición detallada de șu actividad facial revelaría indicios fiables pasados por alto por los observadores, ni si los mismos individuos serían más expresivos en otras situaciones sociales. Los estudios que muestran que la gente puede disimular con éxito sus expresiones emocionales faciales no exploran si esta habilidad es una característica estable de la persona ni si la medición de su actividad facial podría revelar signos fiables (por ejemplo, «filtración») de sus sentimientos reales.

Aparte de las cuestiones de las diferencias individuales y del engaño - que podrían limitar la precisión de la información proporcionada por la expresión facial - hay pocos datos sobre el número y la clase de las situaciones en las que el movimiento facial expresa emociones. Se ha sugerido $(45,46)$ que la mayor parte de la actividad facial en la interacción social tiene poca relación con la emoción, pero ningún estudio empírico ha comparado los diferentes tipos de actividad facial en diferentes situaciones.

3. ¿Qué cantidad de información sabre la emoción proporciona la cara, en comparación con la voz, el lenguaje y el movimiento corporal? Algunos estudios han comparado los juicios de los observadores sobre un hecho percibido a través de distintos canales: audiovisual, auditivo sólo, o visual sólo. La mayoría de los experimentos muestran que la cara es juzgada con mayor exactitud, produce un mayor acuerdo, o correlaciona mejor con juicios basados en una entrada audiovisual completa que la voz o el lenguaje $(5,24,39$, $96,144)$. Unos cuantos experimentos encuentran que la cara es menos importante que otro canal $(7,117)$ o que el canal preponderante variaba según el observador (132). Los hallazgos de la mayoría de los experimentos de "canales» son sospechosos porque la conducta juzgada era bastante artificial. La serie de estudios más amplia (33) sobre la conducta en circunstancias naturales encontró que lo que se decía importaba más que la entrada visual y que el conocimiento de la información demográfica permitía un juicio sobre 
la conducta posterior al menos tan preciso como la exposición a una película sonora.

Otro problema en esta investigación es que a los observadores que juzgan el canal «facial» se les presenten - sin sonido- expresiones faciales que ocurren inmersas en el lenguaje. Esto podría causar una interpretación errónea de las expresiones faciales relacionadas con el lenguaje. Sin embargo, observadores que se limitan exclusivamente a la cara pueden obtener más información que si observaran la cara en su contexto. Un estudio en realización de Ekman, Friesen, O'Sullivan y Scherer encontró que el peso relativo concedido a la expresión facial, el lenguaje y los indicios corporales dependía de la tarea a juzgar (calificar los estímulos, dominancia del sujeto, sociabilidad, relajación) y de las condiciones en que la conducta ocurría (mientras los sujetos describían francamente las reacciones positivas a una película placentera o intentaban ocultar emociones negativas provocadas por una película displacentera). La correlación entre los juicios de los observadores que veían la cara con lenguaje y los que la veían sin él fue bastante baja en algunas escalas (por ejemplo, tranquilo-agitado) y bastante elevada en otras (expansivo-retraído).

Los estudios de Bugental et al., sugieren que la influencia de la expresión facial en comparación con otras fuentes depende del emisor, del receptor, del mensaje contenido en cada canal y de la experiencia previa. Los niños eran menos influidos que los adultos por la sonrisa de una mujer adulta cuando iba acompañada de palabras y tono de voz negativos (21). Se encontró alguna base experimental para desconfiar de las sonrisas maternas en un estudio en que éstas (pero no las del padre) no se relacionaban con el contenido positivo o negativo del lenguaje que las acompañaba (22). Igualmente, las madres (pero no los padres) de niños con trastornos emitían más mensajes discrepantes (entre cara, voz y palabras) que las de niños normales (23).

Aunque Scherer et al. (110) estudiaron los juicios de personalidad más que la emoción, sus resultados contradicen la idea de que un canal es más eficaz que otro. Las inferencias sobre la personalidad dependen, generalmente, cada una de un canal, unas se realizan mejor a partir de una fuente, las demás a partir de otras. Ninguna combinación de canales (cara y lenguaje, cara y voz, etc.) proporcionaba los juicios más exactos. Estos variaban según el rasgo juzgado.

La cuestión global de la información transmitida por canales «aislados» puede conducir inevitablemente a la confusión. No hay ninguna evidencia de que las personas atiendan selectivamente en la interacción social real a la cara de otra persona, al cuerpo, a la voz o al lenguaje, o de que la información enviada a través de estos canales sea simplemente aditiva. Los mecanismos centrales directores de la conducta atraviesan los canales de forma que, por ejem. plo, ciertos aspectos de la cara, el cuerpo, la voz y el lenguaje son más espontáneos mientras que otros son controlados más estrechamente. Pudiera ser que los observadores no atendieran selectivamente a un canal determinado, sino a un tipo particular de información (por ejemplo, indicios de emoción, engaño o actividad cog- 
nitiva) que podría obtenerse de diferentes canales. Ningún investigador ha explorado esta posibilidad o la de que distintas personas atiendan característicamente a diferentes tipos de información.

\section{RETROALIMENTACION FACIAL}

El próximo grupo de estudios está dirigido a la cuestión, largamente debatida, de cómo conocemos lo que sentimos. Desde el ocaso de la teoría de la emoción de James-Lange -que postulaba una retroalimentación visceral y somática como fuente de nuestra experiencia subjetiva de la emoción- han prevalecido las teorías cognitivas. Estas teorías (por ejemplo, Schachter) ven la activación emocional como indiferenciada; nuestra experiencia de una emoción determinada, dicen, resulta de la interpretación de los indicios situacionales. Tomkins $(128,129)$, por el contrario, mantiene que experimentamos emociones discretas, diferenciadas, a través de la retroalimentación de pautas innatas de expresión facial.

Una variante de la hipótesis de la retroalimentación facial, propuesta en el marco de la teoría de la autoatribución, postula que podemos utilizar la información de nuestra conducta facial (y otras) para inferir lo que sentimos. El estudio de Laird (85) proporcionó un modelo para experimentos de retroalimentación posteriores: se instruyó a los sujetos para que contrajeran determinados músculos faciales, produciendo - presumiblemente sin darse cuenta- una expresión «feliz» o «enojada» que mantuvieron mientras veían diapositivas o dibujos. La manipulación de la cara tuvo un efecto significativo aunque pequeño (comparado con el producido por las diapositivas) sobre los sentimientos manifestados. Una serie de experimentos posteriores encontró que las diferencias individuales en la tarea de manipulación de la cara se relacionaban con otros índices de la tendencia de unos sujetos a utilizar indicios «autoproducidos» frente a los «producidos por la situación» (por ejemplo, 41).

Un experimento reciente (Tourangeau y Ellsworth, manuscrito no publicado) no pudo confirmar la versión radical de la hipótesis de la retroalimentación facial de que la expresión facial manifiesta es necesaria y suficiente para la experiencia de la emoción. Las manipulaciones faciales no tuvieron un efecto significativo en la emoción manifestada y sólo efectos ambiguos en las respuestas fisiológicas.

Estos resultados contradictorios son difíciles de evaluar debido a los problemas metodológicos que conlleva el paradigma de manipulación de la expresión: las características de demanda de la tarea, la inverosimilitud de las historias presentadas y la artificialidad de la situación y de las expresiones faciales, que tienen que mantenerse durante largo tiempo de forma no natural. Como Laird (85) advertía, una retroalimentación que es demasiado artificial podría no ser tenida en cuenta por el sujeto (o por el SNC), yendo de esta forma contra la hipótesis.

Las pruebas más claras de la relación positiva entre la expresión facial voluntaria y la experiencia emocional provienen de un conjunto de experimentos de Lanzetta, Kleck y colaboradores (34, 83, 88) que investigaron el efecto de la expresión facial manifiesta sobre 
la intensidad de la activación emocional producida por una descarga. Los intentos de encubrir los signos faciales de dolor condujeron consistentemente a descensos en la conductividad de la piel y en las valoraciones subjetivas del dolor, mientras que el mostrar la expresión de descarga intensa aumentó significativamente ambas medidas de activación. Cuando se indicó a los sujetos que estaban siendo observados por otra persona mostraron expresiones faciales menos intensas $\mathrm{y}$, en correspondencia, disminuyeron las respuestas autónomas y las valoraciones subjetivas de dolor -incluso aunque no recibieron instrucción alguna de que inhibieran sus respuestas (83). Estos resultados se pueden interpretar de diversas formas (véase 88). Antes de concluir que la retroalimentación facial está directa y causalmente relacionada con los cambios observados en la activación, sería necesario descartar la posibilidad de que alguna otra estrategia utilizada por los sujetos hubiera podido afectar a la expresión facial y a la experiencia emocional al mismo tiempo. Tampoco parece claro que el efecto sea específico de los signos faciales de la emoción frente a los corporales. Sin embargo, los resultados sugieren que la expresión facial manifiesta puede influir en la intensidad de la activación emocional. La evidencia de que la retroalimentación facial puede determinar quê emoción experimentamos es más ambigua. Debe resaltarse lo poco que se sabe de la naturaleza y cualidad de la retroalimentación de los músculos de la expresión facial.

\section{CONTROL NEURAL Y CORRELATOS AUTONOMOS DE LA EXPRESION FACIAL}

\section{Correlatos psicofisiológicos:}

El estudio de la relación entre la expresión facial y las respuestas del SNA ha tenido dos enfoques diferentes. En un tipo de estudio se comparaban cambios importantes en medidas autónomas (generalmente la RGP) promediadas para cierto periodo y cambios de la expresión facial (a partir de los juicios de los observadores de la emoción). El otro enfoque buscaba pautas, momento a momento, en los cambios de las medidas autónomas y faciales. Esta aproximación ha conseguido resultados más consistentes.

Los estudios correlacionales de las diferencias individuales en responsividad del SNA y la expresividad facial (en los estudios de codificación-descodificación discutidos anteriormente) han encontrado normalmente relaciones negativas: por ejemplo, los sujetos cuyas caras podían juzgarse con precisión como anticipadoras de una descarga (89) o viendo diapositivas que provocaban emociones positivas o negativas, mostraban respuestas RGP más bajas y viceversa (revisado en 17). Sin embargo, en estudios experimentales intrasujetos (por ejemplo, la retroalimentación facial y los estudios sobre el engaño ya discutidos), los aumentos en expresividad facial iban acompañados de aumentos en la responsividad del SNA (88, véanse otros estudios recientes citados más arriba). 
Malmstrom, Ekman y Friesen (147), en un estudio piloto, encontraron que las diferentes pautas de aceleración y deceleración del ritmo cardíaco coincidían con una actividad facial que mostraba elementos de desagrado frente a sorpresa cuando los sujetos veían una película generadora de estrés. Ancoli (4) encontró que las expresiones faciales de desagrado en sujetos que veían una película displacentera se relacionaban con cambios respiratorios (torácicos en comparación a abdominales).

En estudios evolutivos sobre las reacciones de los niños a un extraño que se aproximaba, diversos investigadores (por ejemplo, 26; 136, revisado en 120) han encontrado una mayor aceleración del ritmo cardíaco en niños de 6 a 10 meses que mostraban signos faciales de «recelo» o inquietud que en niños que mostraban expresiones normales o positivas. Una cara atenta, «abierta» o afectivamente neutra iba acompañada normalmente de una disminución del ritmo cardíaco. Lewis, Brooks y Haviland (91), aunque encontraron una relación entre deceleración del ritmo cardíaco y expresiones de atención, no hallaron una relación significativa entre aceleración cardíaca y expresiones emocionales negativas.

\section{La cara y el cerebro}

La mayor parte del conocimiento sobre el control neural de la expresión facial proviene de estudios clínicos de los desórdenes neurológicos. El control dual del movimiento facial aparece en el hallazgo de que las personas que padecen parálisis completa de los movimientos faciales voluntarios (como en la parálisis pseudobulbar, que afecta al tracto corticobulbar) pueden mostrar expresiones faciales espontáneas -a menudo exageradas - cuando se activa la emoción (58) Por el contrario, la expresión emocional espontánea puede ser afectada por las lesiones subcorticales, el parkinsonismo postencefalítico o la «debilidad congénita de los músculos faciales», aunque no pasa lo mismo con los movimientos voluntarios (58). Se sabe que el sistema límbico es importante en la expresión emocional (revisado en 87) y los sucesivos estados en el desarrollo ontogenético de la expresión facial y vocal, espontánea y voluntaria, están probablemente relacionados con la maduración de estructuras y subsistemas específicos del cerebro, aunque hasta el presente la evidencia es indirecta $y$, a menudo, superficial.

Algunas líneas convergentes (estudios de lesiones cerebrales, investigación sobre pacientes con la comisura seccionada, experimentos de tiempos de reconocimiento y reacción en sujetos normales) apuntan hacia una ventaja del hemisferio derecho en el reconocimiento de caras. Esta superioridad es especialmente pronunciada cuando la tarea requiere el procesamiento en términos de orden superior, de propiedades configuracionales de las caras más que de. rasgos aislados $(25,40)$. Es mayor también (126) cuando las caras que los sujetos deben reconocer muestran expresiones emocionales que cuando son afectivamente neutras. La habilidad en la utilización de la información configuracional para el reconocimiento de caras desconocidas no se desarrolla hasta alrededor de los 10 años. Los niños menores -al igual que los pacientes con lesiones del 
hemisferio derecho- procesan fragmentariamente y pueden ser engañados con facilidad por la apariencia externa, como las prendas de vestir (40). No se encontró que la expresión facial fuera una fuente de confusión en niños de cualquier edad, lo que hace suponer que - a diferencia del vestido- no se percibe como un indicio aislado para identificar sino más bien unido a propiedades configuracionales de orden superior de las caras. Este punto de vista se confirmó con el hallazgo de Campbell (resultados sin publicar) de que la expresión facial confunde a menudo a los adultos cuando los estímulos faciales se proyectan en el hemisferio derecho pero no en el izquierdo (véase también 35 ).

Campbell ( 25 y resultados sin publicar) utilizó estímulos faciales irreales (compuestos por dos medias caras que representaban diferentes individuos o expresiones faciales, o bien expresiones invertidas en un espejo) para estudiar los efectos de la lateralización en la producción y percepción de la expresión facial. Sus hallazgos revelan que -en adultos diestros- la percepción de la expresión facial está dominada por el campo visual izquierdo (es decir, el hemisferio derecho del sujeto) que se corresponde con el lado derecho de los estímulos faciales. Al mismo tiempo, la emoción puede expresarse realmente con más intensidad en el lado izquierdo de la cara, controlado por el hemisferio derecho. Los estudios de lesiones (por ejemplo, 18) proporcionan una mayor evidencia de la superioridad del hemisferio derecho en la expresión emocional.

\section{DIRECCIONES FUTURAS}

El estudio de la expresión facial promete una visión nueva de una gran variedad de problemas psicológicos. Hasta ahora hemos revisado estudios que indican la relevancia de la expresión facial para la investigación en Psicología evolutiva, percepción de la persona, teorías de la emoción y neurofisiología de la emoción. Permanece sin explorar la relevancia de la expresión facial - y de los hipotéticos estilos de control de la expresión emocional $(49,78$, 128) - en los desórdenes de la personalidad y en enfermedades psicosomáticas. Tampoco se ha estudiado la relación - verdadera o percibida - entre expresión facial e inteligencia, cuestión importante en la evaluación del CI (72).

Para terminar, citaremos varios hallazgos recientes que muestran cómo el estudio de la expresión facial puede ayudar a entender algunos de los aspectos prácticos de- la interacción social. En una tarea de aprendizaje, el profesor castigaba menos a los sujetos que parecían irritados que a los alegres (109). Los alumnos aprenden más con un profesor que presenta más expresiones emocionales positivas que negativas durante la explicación (60). Los niños que parecían más alegres que tristes mientras veían escenas violentas en la TV mostraban a continuación una conducta más agresiva que altruista (54). Los sujetos con una puntuación alta en «humanitarismo» sonreían más a menudo en la conversación que los sujetos «no humanitarios» (134). El tipo de movimiento facial empleado para dar 
énfasis al lenguaje (46) o indicar una pregunta (Camras, comunicación personal) se relaciona con el papel hipotético de los movimientos en la expresión facial, y el uso diferencial de acciones faciales concretas para realzar el lenguaje afecta a las impresiones transmitidas a los demás (101).

\section{Referencias}

1. Answorth, M.: «The development of infant-mother attachment», en Review of Cbild Development Research, vol. 3, ed. B. Caldwell, H. Ricciuti, Chicago, Chicago Univ. Press, 1-94, 1973.

2. Allport, F. M.: Social Psychology, Boston, Houghton Mifflin, 1924.

3. Altmann, S.: «Primates», en Animal Communication: Tecbniques and Results of Researcbs, ed. T. Sebeok, Bloomington, Indiana Univ. Press, 466-522, 1968.

4. Ancoli, S.: Psychophysiological response patterns to emotions, Tesis Ph. D., Univ. California, San Francisco, California, 1978.

5. Argyle, M.; Alrema, F.; Gilmour, R.: «The communication of friendly and hostile attitudes by verbal and nonverbal signals», Eur. J. Soc. Psychol, 1 (3), 385-402, 1971.

6. BELL, S. M.; AINSwORTH, M. D. S.: «Infant crying and maternal responsiveness», Child Dev, 43, 1171-90, 1972.

7. Berman, H. J.; Shulman, A. D.; Marwit, S. J.: «Comparison of multidimensional decoding of affect from audio, video and audiovideo recordings», Sociometry, 39 (1), 83-89, 1976.

8. Birdwhistell, R. L.: Kinesics and Context, Philadelphia, Univ. Pennsylvania Press, 1970.

9. BluRton JonEs, N. G.: «Criteria for use in describing facial expressions in children», Hum. Biol., 41, 365-413, 1971.

10. BluRton Jones, N. G.: «Non-verbal communication in children», en Nonverbal Communication, ed. R. A. Hinde, Cambridge, Inglaterra, Cambridge Univ. Press, 271-96, 1972.

11. Boucher, J. D.: Facial bebavior and the perception of emotion: Studies of Malays and Temuan Orang Asli. Presentado en la Conf. Psychol. Related Disciplines, Kuala Lumpur, 1973.

12. BowlBy, J.: Attacbment and Loss, vol. 1, Attacbment, Nueva York, Basic Books, 1969.

13. Brannigan, C. R.; Humpriese, D. A.: «Human nonverbal behavior, a means of communication», en Ethological Studies of Child Behavior, ed. N. G. Blurton Jones, Cambridge, Cambridge Univ. Press, 1972.

14. Brazelton, T.; Tronick, E.; Adamson, L.; Als, H.; Wise, S.: «Early mother-infant reciprocity", Parent-Infant Interaction, Amsterdam, Elsevier Exp. Med., 1975.

15. BRUner, J. S.; TAgiuri, R.: «The perception of people», en Handbook of Social Psycbo logy, vol. 2, ed. G. Lindzey, Reading, Mass: Addison-Wesley, 1954.

16. Buck, R.: «Nonverbal communication of affect in children», J. Pers. Soc. Psycbol, 31, 64453, 1975.

17. Bucx, R.: Measuring individual differences in the nonverbal communication of affect: The slide viewing paradigm. Presentado en Am. Psychol. Assoc. meet., San Francisco, 1977.

18. Buck, R.; DUFFY, R.: Nonverbal communication of affect in braindamaged patients. Presentado en Am. Psychol. Assoc. meet., San Francisco, 1977.

19. BuCk, R.; Miller, R. E.; CAUl, W. F.: «Sex, personality, and physiological variables in the communication of affect via facial expression», J. Pers. Soc. Psychol, 30 (4), 587-96, 1974.

20. Buck, R.; Savin, V. J.; Miller, R. E.; Caul, W. F.: «Communication of affect through facial expressions in humans», J. Pers. Soc. Psycbol, 23, 362-71, 1972.

21. Bugental, D.; Kaswan, J.; Love, L.; Fox, M.: «Child versus adult perception of evaluative messages in verbal, vocal and visual channels", Dev. Psycbol, 2 (3), 367-75, 1970.

22. Bugental, D.; Love, L.; Gianetto, R.: «Perfidious feminine faces», J. Pers. Soc. Psychol, 17 (3), 314-18, 1971.

23. Bugental, D.; Love, L.; Kaswan, J.; April, C.: «Verbal-nonverbal conflict in parental messages to normal and disturbed children», J. Abnorm. Psycbol, 77 (1), 6-10, 1971. 
24. Burns, K. L.; BeIER, E. G.: «Significance of vocal and visual channels in the decoding of emotional meaning», J. Commun., 23, 118-30, 1973.

25. Campbel1, R.: «Asymmetries in interpreting and expressing a posed facial expression», Cortex, en prensa, 1978.

26. Campos, J. J.; Emde, R. N.; Gaensbauer, T.; Henderson, C.: «Cardiac and behavioral interrelationships in the reactions of infants to strangers», Dev. Psycbol, 11 (4), 589-601, 1975.

27. Campos, J. J.; Hiatt, S.; Ramsay, D.; Henderson, C.; Svejda, M.: «The emergence of fear on the visual cliff», en The Development of Affect, ed. M. Lewis, L. Rosenblum, 149-82, Nueva York: Plenum, 1978.

28. Camras, L.: «Facial expressions used by children in a conflict situation», Child Dev., 48, 1431-35, 1977.

29. Chapman, A. J.; Wright, D. S.: «Social enhancement of laughter: An experimental analysis of some companion variables», J. Exp. Child Psychol, 21, 201-18, 1976.

30. Charlesworth, W. R.; Kreutzer, M. A.: «Facial expression of infants and children», en Darwin and Facial Expression, ed. P. Ekman, Nueva York: Academic, 91-168, 1973.

31. Chevalier-Skolnikoff, S.: «Facial expression of emotion in non-human primates», véase Ref. 30, 11-89, 1973.

32. Cicchetri, D.; Sroufe, L. A.: «An organizational view of affect: Illustration from the study of Down's Syndrome infants», véase Ref. 27, 309-50, 1978.

33. Cline, V. B.; Atzer, J.; Holmes, E.: «Assessing the validity of verbal and nonverbal cues in accurately judging others», Comp. Group Stud, 3, 383-94, 1972.

34. Colby, C. Z.; Lanzetta, J. T.; Kleck R. E.: «Effects of the expression of pain on autonomic and pain tolerance responses to subject-controlled pain», Psycbopbysiology, $14(6), 537-40,1977$.

35. CRouCH, W. W.: «Dominant direction of conjugate lateral eye movements and responsiveness to facial and verbal cues», Percept. Mot. Skills, 42, 167-74, 1976.

36. Cunningham, M. R.: «Personality and the structure of the nonverbal communication of emotion», J. Pers., 45, 564-84, 1977.

37. Darwin, C.: The Expression of Emotion in Man and Animals, Nueva York, Philosophical Library (publicado originalmente en 1872), 1955.

38. Decarie, T.: "Affect development and cognition in a Piagetian context», véase Ref. 27, 183-204, 1978.

39. DePaulo, B.; Rosenthal, R.; Eisenstat, R.; Finkelstein, S.; Rogers, P.: «Decoding discrepant nonverbal cues», J. Pers. Soc. Psychol, en prensa, 1978.

40. Diamond, R.; Carey, S.: «Developmental changes in the representation of faces», J. Exp. Cbild Psychol, 23, 1-22, 1977.

41. DunCan, J.; LAIRD, $J$. D.: «Crossmodality consistencies in individual differences in selfattribution», J. Pers., 45 (2), 191-206, 1977.

42. Eibl-Eibesfeldt, I.: «Similarities and differences between cultures in expressive movements», véase Ref. 10, 297-312, 1971.

43. Ekman, P.: «Universals and cultural differences in facial expressions of emotion», Nebr. Symp. Motiv., 207-83, 1971, 1972.

44. Ekman, P.: «Cross cultural studies of facial expression», véase Ref. 30, 169-229, 1973.

45. Exman, P.: «Biological and cultural contributions to body and facial movement», en The Antropology of the Body, ed. J. Blacking, Londres, Academic, 1977.

46. Exman, P.: «About brows: Emotional and conversational signals», en Human Etbology, ed. J. Aschoff, M. von Cranach, K. Foppa, W. Lepenies, D. Ploog, Cambridge, Cambridge Univ. Press, en prensa, 1978.

47. Ekman, P.; Friesen, W. V.: «Constants across cultures in the face and emotion», J.. Pers Soc. Psychol., 17, 124-29, 1971.

48. Ekman, P.; Friesen, W. V.: «Detecting deception from the body or face», J. Pers. Soc. Psychol., 29 (3), 288-98, 1974.

49. Ekman, P.; Friesen, W. V.: Unmasking the Face, Englewood Cliffs, NJ: Prentice-Hall, 1975.

50. Ekman, P.; Friesen, W. V.: «Measuring facial movement», J. Environ. Psychol. Nonverb. Behav., 1 (1), 56-75, 1976.

51. Ekman, P.; Friesen, W. V.: The Facial Action Coding System, Palo Alto, Calif., Consult. Psychol. Press, 1978.

52. Ekman, P.; Friesen, W. V.; Ellsworth, P.: Emotion in the Human Face, Elmsford, NY: Pergamon, 1972.

53. Ekman, P.; Friesen, W. V.; Tomkans, S. S.: «Facial Affect Scoring Technique (FAST): A first validity study», Semiotica, 3 (1), 37-38, 1971. 
54. Ekman, P.; Liebert, R. M.; Friesen, W. V.; Harrison, R. A.; Zlatchin, C.; MalmsTROM, E. J.; BARON, R. A.: «Facial expressions of emotion while watching televised violence as predictors of subsequent aggression», en Television and Social Behavior Vol. V.: Television's Effects: Further explorations, ed. G. A. Comstock, E. A. Rubinstein, J. P. Murray. Informe técnico del Surgeon General's Scientific Advisory Committee on Television and Social Behavior, Washington, DC: GPO, 1972.

55. Ekman, P.; Sorenson, E. R.; FrIESEN, W. V.: «Pan-cultural elements in facial displays of emotion", Science, 164 (3875), 86-88, 1969.

56. Emde, R. N.; Gaensbauer, T. J.; Harmon, R. J.: «Emotional expression in infancy: A biobehavioral study», Psycbol. Issues Monogr. Ser., 10, Monogr. 37, 1976.

57. ERmaine, R.; Gregerian, E.: Atlas of Facial Expressions. Album des expressions du visage, París: La Pensée Universelle, 1978.

58. Ford, F. R.: Diseases of the Nervous System in Infancy, Cbildbood, and Adolescence, Springfield, Ill: Thomas, 5." ed., 1966.

59. FraiberG, S.: «Blind infants and their mothers: An examination of the sign system», véase Ref. 92, 215-32, 1974.

60. FRIED, E.: The impact of nonverbal communication of facial affect on children's learning. Tesis Ph. D., Rutgers Univ., New Brunswick, NJ, 1976.

61. FRIESEN, W. V.: Cultural differences in facial expressions in a social situation: An experimental test of the concept of display rules. Tesis $\mathrm{Ph}$. D. Univ. California, San Francisco, 1972.

62. Fuytr, B.: Encoding and decoding of spontaneous and enacted facial expressions of emotion. Tesis Ph. D. Univ. Oregon, Portland, 1977.

63. GeSELl, A.: The Embryology of Bebavior, Nueva York: Harper, 1945.

64. GewirTz, J. L.; BoYd, E. F.: «Mother-infant interaction and its study», Adv. Child Dev. Behav., 11, 141-63, 1976.

65. Graham, J. A.; Argyle, M.: «The effects of different patterns of gaze combined with different facial expressions, on impression information», J. Hum. Movement Stud., 1, 178-82, 1975.

66. Grant, N. G.: «Human facial expression», Man, 4, 525-36, 1969.

67. Greenspan, S.; Barenboim, C.; Chandler, M. J.: «Empathy and pseudoempathy: The affective judgments of first- and third-graders», J. Genet. Psychol., 129, 77-88, 1976.

68. Hall, J.: «Gender effects in decoding nonverbal cues», Psychol. Bull., en prensa, 1978.

69. Hall, J.: «Gender effects in necoding nonverbal cues», Psychol. Bull., en prensa, 1978.

70. Hamrton, M. L.: "Imitative behavior and expressive ability in facial expression of emotion», Dev. Psychol., 8 (1), 138, 1973.

71. Harper, R. G.; Wiens, A. N.; Fujita, B.: «Individual differences in encoding-decoding of emotional expression and emotional dissimulation». Presentado en Am. Psychol. Assoc. meet., San Francisco, 1977.

72. Haviland, J.: "Looking smart: The relationship between affect and intelligence in infancy», en Origins of Infant Intelligence, ed. M. Lewis, Nueva York: Plenum, 1975.

73. Heider, K.: Affect display rules in the Dani. Presentado en Am. Anthropol. Assoc. meet., Nueva Orleans, 1974.

74 Hiatt, S.; Campos, J.; Emde, R.: Fear, surprise, and happines: The patterning of facial expression in infants. Presentado en Soc. Res. Child Dev., Nueva Orleans, 1977.

75. Hoffman, M. L.: «Empathy, its development and prosocial implications», Nebr. Symp. Motiv., 25, en prensa, 1977.

76. Hunt, W. A.: «Recent developments in the field of emotion», Psychol. Bull., 38 (5), 249-76, 1941.

77. Izard, C.: The Face of Emotion, Nueva York: Appleton-Century-Crofts, 1971.

78. IzArD, C.: Human Emotions, Nueva York, Londres: Plenum, 1977.

79. IZARD, C.: "On the ontogenesis of emotions and emotion-cognition relationships in infancy», véase Ref. 27, 389-413, 1978.

80. JACOBSON, S.; KAGAN, J.: Released responses in early infancy: Evidence contradicting selective imitation. Presentado en Int. Conf. Infant Stud., Providence, R.I., 1978.

81. Josse, D.; Leonard, M.; Lezine, I.; Robinot, F.; Rouchouse, J.: «Evolution de la communication entre l'enfant de 4 a 9 mois et un adulte», Enfance, 3 (4), 175-206, 1973.

82. KaYe, K.; Marcus, J.: «Imitation over a series of trials without feedback: Age six monthsm, Infant Bebav. Dev., 1, 141-55, 1978.

83. Kleck, R. E.; Vaughan, R. C.; Cartwright-Smith, J.; Vaughan, K. B.; Colby, C. Z.; LANZETTA, J. T.: «Effects of being observed on expresive, subjective, and physiological responses to painful stimuli», J. Pers. Soc. Psychol., 34, 1211-18, 1976. 
84. Labarbera, J. D.; Izard, C.; Vietze, P.; Parisi, S. A.: «Four- and six-monthold infants' visual responses to joy, anger, and neutral expressions», Child Dev., 47, 535-38, 1976.

85. LaIRD, J. D.: «Self-attribution of emotion: The effects of expressive behavior on the quality of emotional experience», J. Pers. Soc. Psychol., 29 (4), 475-86, 1974.

86. Lalljee, M.: «The role of gaze in the expression of emotion», Aust. J. Psychol., en prensa, 1978.

87. Lamendella, J. T.: «The limbic system in human communication», en Studies in Neurolinguistics, vol. 3, ed. H. Whitaker, H. A. Whitaker, Nueva York: Academic, 1977.

88. Lanzetta, J. T.; Cartwright-Smith, J.; Kleck, R. E.: «Effects of nonverbal dissimulation on emotional experience and autonomic arousal», J. Pers. Soc. Psychol., 33 (3), $35470,1976$.

89. LANZETTA, J. T.; KLECR, R. E.: «Encoding and decoding of nonverbal affects in humans», J. Pers. Soc. Psychol., 16, 12-19, 1970.

90. LewIS, M.; Brooks, J.: «Self-knowledge and emotional development, véase Ref. 27, 205-26, 1978.

91. LEwis, M.; Broors, J.; Haviland, J.: «Hearts and faces: A study in the measurement of emotion", véase Ref. 27, 77-124, 1978.

92. Lewis, M.; Rosenblum, L. A., eds.: The Effect of the Infant on its Caregiver, Nueva York: Wiley, 1974.

93. McGREw, W. C.: An Ethological Study of Children's Bebavior, Nueva York: Academic, 1972.

94. MeAD, M.: «Review of Darwin and Facial expression, ed. P. Ekman, J. Commun, 25 (1), 209-13, 1975.

95. Merrabian, A.: «Nonverbal betrayal of feeling», J. Exp. Res. Pers., 5 (1), 6473, 1971.

96. Mehrabian, A.; Ferris, S.: «Inference of attitudes from nonverbal communication in two channels», J. Consult. Psychol., 31 (3), 248-52, 1967

97. Meltzoff, A. N.; Moore, M. K.: «Imitation of facial and manual gestures by human neonates», Science, 198, 75-78, 1977.

98. NyStRom, M.: «Neonatal facialpostural patterning during sleep: I. Description and reliability of observation, Psycbol. Res. Bull., 14, 7, 1974.

99. Oster, H.: «Facial expression and affect development», véase Ref. 27, 43-76, 1978.

100. Oster, H.; Ekman, P.: «Facial behavior in child development», Minn. Symp. Child Psycbol., 11, 231-76, 1978.

101. O'Sullivan, M.; Eyman, J.: «Signal value of eyebrow movements in conversation». Presentado en West. Psychol. Assoc. meet., San Francisco, 1978.

102. Papouser, H.; Papouser, M.: «Mothering and the cognitive head-start: psychobiological considerations», en Studies in Motber-Infant Interaction, ed. H. R. Schaffer, 63-85, Nueva York: Academic, 1977.

103. Pieper, A.: Cerebral Function in Infancy and Childbood, Nueva York: Consultants Bureau, 1963.

104. Redican, W. K.: «Facial expression in nonhuman primates», en Primate Bebavior, vol. 4, ed. L. A. Rosenblum, Nueva York: Academic, 1975.

105. Roper, G.: The development of voluntary facial imitation in children. Tesis $\mathrm{M}$. A. San Francisco State Univ., San Francisco, Calif., 1977.

106. SaArni, C.: Acquisition of display rules for expressive bebavior. Presentado en East. Psychol. Assoc. meet., Washington DC, 1978.

107. SAARNI, C.: «Cognitive and communicative features of emotional experience, or do you show what you think you feel?, véase Ref. 27, 367-76, 1978.

108. SAHA, G. B.: «Judgment of facial expression of emotion-a cross-cultural study», J. Psycbol. Res., 17 (2), 59-63, 1973.

109. Savitsky, J. C.; IzARd, C. E.; Kotsch, W. E.; Christr, L.: «Aggressors's response to the victim's facial expression of emotion», J. Res. Pers., 7, 346-57, 1974.

110. Scherer, K. R.; Scherer, U.; Hall, J. A.; Rosenthal, R.: «Differential attribution of personality based on multichannel presentation of verbal and nonverbal cues», Psychol. Res., 39, 221-47, 1977.

111. SChiffendauer, A.: \&Effect of observer's emotional state on judgments of the emotional state of others», J. Pers. Soc. Psycbol., 30 (1), 31-35, 1974.

112. Schlosberg, H.: «The description of facial expressions in terms of two dimensions», 497-510, 1941.

113. Schlosberg, H.: «The description of facial expressions in terms of two dimensions», J. Exp. Psycbol., 44, 229-37, 1952.

114. SChlosberg, H: «Three dimensions of emotion», Psychol. Rev., 61, 81-88, 1954.

115. Schwartz, G. E.; Fair, P. L.; Salt, P.; MandeI, M. K.; Klerman, G. L. «Facial mus- 
cle patterning to affective imagery in depressed and non-depressed subjects», Science, 192 (4238), 489-91, 1976.

116. SEAFORD, H. W.: Maximizing replicability in describing facial bebavior. Presentado en Am. Anthropol. Assoc. meet., Washington DC, 1976.

117. ShapIRo, J. G.: «Variability and usefulness of facial and body cues», Comp. Group Stud., 3 (4), 437-42, 1972.

118. ShUlTZ, T. R.; ZigleR, E.: «Emotional concomitants of visual mastery in infants: The effects of stimulus movement on smiling and vocalizing», J. Exp. Cbild Psycbol., 10, 390-402, 1970.

119. Sмiтh, R. P.: «Frontalis muscle tension and personality», Psycbopbysiology, 10 (3), 311-12, 1973.

120. SROufE, L. A.: «Wariness of strangers and the study of infant development», Child Dev., $48,731-46,1977$.

121. SRoufe, L. A.: :The ontogenesis of emotion", en Handbook of Infancy, ed. J. Osofosky, Nueva York: Wiley, en prensa, 1978.

122. SRoufe, L. A.; WATERS, E.: «The ontogenesis of smiling and laughter: A perspective on the organization of development in infancy», Psycbol. Rev., 83, 173-189, 1976.

123. Stechler, G.; Carpenter, G.: «A viewpoint on early affect development», en Exceptional Infant, vol I; The Normal Infant, ed. J. Hellmuth, Nueva York, Brunner/Mazel, 1967.

124. StEINER, J. E.: «The gustofacial response: Observation on normal and anencephalic newborn infants», en Fourth Symposium on Oral Sensation and Perception, ed. J. F. Bosma, Bethesda, Md: US Dep. HEW, 1973.

125. Stern, D. N.; BeEbe, B.; JAFFe, J.; BennetT, S. L.: «The infant's stimulus world during social interaction: A study of caregiver behaviours with particular reference to repetition and timing», véase Ref. 103, 177-202, 1978.

126. SUbERI, M.; MCKEEVER, W. F.: «Differential right hemispheric memory storage of emotional and non-emotional faces», Neuropsycbologia, 15, 757-68, 1977.

127. TAgiurI, R.: «Person perception», en The Handbook of Social Psychology, ed. G. Lindzey, E. Aronson, Reading, Mass: Addison-Wesley, 1968.

128. Tomkins, S. S.: Affect, Imagery, Consciousness, vol. 1, The Positive Affects, Nueva York: Springer, 1962.

129. Tomkins, S. S.: Affect, Imagery, Consciousness, vol. 2, The Negative Affects, Nueva York: Springer, 1963.

130. Tomkins, S. S.; McCarter, R.: «What and where are the primary affects? Some evidence for a theory», Percept. Mot. Skills, 18, 119-58, 1964.

131. Trevarthen, C.: «Descriptive analyses of infant communicative behavior», véase Ref. 103, 227-70, 1977.

132. VANDE CreER, L.; Watrins, J. T.: «Responses to incongruent verbal and nonverbal emotional cues», J. Commun, 22, 311-16, 1972.

133. VAN HoofF, J. A. R. A. M.: «A comparative approach to the phylogeny of laughter and smiling», véase Ref. 10, 209-38, 1972.

134. Vasquez, J.: The face and ideology. Tesis Ph. D. Rutgers Univ., New Brunswick, NJ, 1975.

135. Vaughn, B. E.; Sroufe, L. A.: The face of surprise in infants. Presentado en Animal Behav. Soc. meet., Boulder, Colo, 1976.

136. Waters, E.; Matas, L.; Sroufe, L.: «Infants' reaction to an approaching stranger: Description, validation, and functional significance of wariness», Child Dev., 46, 348-56, 1975.

137. WATSON, J. S.: «Perception of contingency as a determinent of social responsiveness», en The Origin of the Infant's Social Responsiveness, ed. E. P. Thoman, Hillsdale, NJ: Erlbaum, en prensa, 1978.

138. Winkelmayer, R.; Exline, R. V.; Gottheil, E.; Paredes, A.: «The relative accuracy of U.S., British, and Mexican raters in judging the emotional displays of schizophrenic and normal U.S. women», J. Clin. Psychol., en prensa, 1978.

130. Tomkins, S. S.; MCCARTER, R.: \&What and where are the primary affects? Some evidenof Infant Bebavior II, ed. B. M. Foss. Nueva York: Willey, 1963.

140. WoLFF, P. H.: «The causes, controls, and organization of behavior in the neonate», Psychol. Issues, 5, Monogr. 17, 1966.

141. WoLfF, P. H.: "The natural history of crying and other vocalizations in early infancy», en Determinants of Infant Bebavior IV, ed. B. M. Foss. Londres: Methuen, 1969.

142. Young, G.; DECARIE, T. G.: «An ethology-based catalogue of facial/vocal behaviors in infancy», Anim. Bebav., 25 (1), 95-107, 1977.

143. Young-Browne, G.; Rosenfeld, H. M.; Horowitz, F. D.: «Infant discrimination of facial expressions», Child Dev., 48, 555-62, 1977. 


\section{4}

\section{Estudios}

144. Zamel, S.; Merrabian, A.: \&The ability to communicate and infer positive and negative attitudes facially and vocally», J. Exp. Res. Pers., 3, 233-41, 1969.

145. Zuckerman, M.; DeFrank, R. S.; Hali, J. A.; Rosenthal, R.: «Nonverbal encoding and decoding of pleasant and unpleasant affects and of honest and deceptive messages", J. Pers. Soc. Psycbol., en prensa, 1978.

146. Zuckerman, M.; Hall, J.; DeFrans, R. S.; Rosenthal, R.: «Encoding and decoding of spontaneous and posed facial expressions», J. Pers. Soc. Psycbol., 34 (5), 966-77, 1976.

Añadido en pruebas:

147. Malmstrom, E.; Ekman, P.; Friesen, W. V.: Autonomic cbanges with facial displays of surprise and disgust. Presentado en West. Psychol. Assoc. Meet., Portland, Ore, 1972. 